\title{
Smoking Prevalence, Willingness to Quit and Factors Influencing Smoking Cessation among University Students in a Western Nigerian State
}

\author{
Oluwole Adeyemi Babatunde ${ }^{1}$, Olumide Adebayo Omowaye ${ }^{1}$, Damilola Adigun Alawode ${ }^{1}$, Owen Omede ${ }^{1}$, \\ Charles Oluwatemitope Olomofe ${ }^{1}$ \& Juwon Akinyandenu ${ }^{2}$ \\ ${ }^{1}$ Department of Community Medicine, Federal Medical Center, Ido-Ekiti, Nigeria \\ ${ }^{2}$ Department of Family Medicine, Federal Medical Center, Ido-Ekiti, Nigeria \\ Correspondence: Oluwole Adeyemi Babatunde, Department of Community Medicine, Federal Medical Center, \\ Ido-Ekiti, Nigeria. Tel: 234-80-3431-4305. E-mail: wolleking@yahoo.com
}

Received: January 19, 2012

Accepted: March 5, 2012 Published: June 1, 2012

doi:10.5539/ass.v8n7p149

URL: http://dx.doi.org/10.5539/ass.v8n7p149

\begin{abstract}
Background: In order to increase the proportion of successful attempts to quit smoking, it is important to understand the characteristics of smokers who successfully quit smoking. This study seeks to find out the smoking prevalence, the level of willingness to quit and factors influencing smoking cessation among university students in a western Nigerian state.

Methodology: This study was a descriptive cross-sectional study carried out among young adults in tertiary institutions. A sample size of 300 was determined using Fishers formula while multi stage sampling technique was used to select respondents. The questionnaire was semi-structured, pretested and self administered. Analysis was done using Epi-Info version 3.4.1. Frequency tables and cross-tabulations were generated with a statistical significance p-value pre-determined at less than 0.05 .

Results: The number of respondents that ever smoked was 66 (22\% of the total number of respondents) out of which $25(38 \%)$ have ceased smoking while $41(62 \%)$ currently smoke. Those willing to quit out of the 41 that currently smoke are $16(39 \%)$ while $25(61.0 \%)$ were not willing to quit. Of the respondents that ever smoked, the main location of smoking was parties/clubs (50\%), while friends $(53 \%)$ were found to be the main influence to smoke. Willingness to quit smoking was expressed by $16(39.0 \%)$ of current smokers. Among respondents that ever smoked, 55(83.3\%) attempted to quit out of which $41(74.5 \%)$ did as a result of health problems. Factors that positively affected smoking cessation were older age group of 26-30 (100\%), belief that smoking can lead to premature death $(47.1 \%)$ and never being asked to quit smoking $(68.4 \%)$ with statistically significant $\mathrm{p}$ values.

Conclusion: Influence of friends and going to parties/clubs are major factors contributing to smoking habit. Diagnosis of health problems play a major role in attempts to quit smoking while belief that smoking can lead to premature death is a major factor influencing smoking cessation. Being asked to quit smoking without a good understanding of the attendant health hazards does not contribute positively to successful smoking cessation. Peer education in schools emphasizing knowledge of the health implications of smoking as well as early diagnosis of smoking related health problems will go a long way in encouraging smoking cessation.
\end{abstract}

Keywords: smoking prevalence, willingness to quit, smoking cessation

\section{Introduction}

Tobacco smoking is a leading cause of preventable morbidity and death worldwide (Zila et al 2010). Tobacco use is the leading preventable cause of death and disability in developed countries such as Canada, United Kingdom, and Australia, as well as the leading contributor to the socioeconomic disparities in health observed in these countries (Reid et al 2010, Reitzel et al 2010). Smoking is a behaviour that starts in adolescence for $90 \%$ of adults (Etter et al 2002) with an average age of onset ranging between 13-15 years (El-Mhamdi et al 2011, Fawibe et al 2011, Feryal et al 2009) and an overt male preponderance (El-Mhamdi et al 2011, Akindele et al 2010, Salawu et al 2010). 
Tobacco use accounts for approximately 1 million premature deaths annually in China (Ceraso et al 2009). In Germany alone, the mortality due to smoking is estimated at 100,000 to 140,000 deaths a year (Breitling et al 2009). According to the World health Organisation (WHO), tobacco use is currently responsible for the death of one of ten adults worldwide (about 5 million deaths each year) (Ahmed et al 2008). Research suggests that smoking and second hand smoke exposure combined were responsible for 438,000 premature deaths. Also it is estimated that there will be a doubling of deaths from smoking from 5 million per year to approximately 10million per year in 2020 (Warren et al 2008).

The prevalence of smoking in a research done in Saudi Arabia was 28\% (Al-Mohamed et al 2010) while in Kampala and Lilongwe it was 5.6\% and 6.2\% (Muula et al 2007) respectively. In a study done in Nigeria, 20.5\% ever smoked, out of which $11.6 \%$ were current smokers (Akindele et al 2010). Ever smoked is defined as those who have taken up to 100 sticks of cigarette in their lifetime, irrespective of whether he/she still smokes (Husten 2007).

In a similar study in China $61 \%$ had a history of smoking out of which $48 \%$ currently smoke while $13 \%$ were ex-smokers and about half of the current smokers have tried quitting but failed (Al-Mohamed et al 2010). In the last 40 years, there has been a steady decline in smoking prevalence among young adults in the US, but despite these improvements, $26 \%$ of young adults smoke, which is the highest smoking prevalence of any adult age group in the world (Audrain-Mcgovern et al 2009).

Although, the smoking prevalence has decreased in recent decades, it is becoming increasingly concentrated among individuals with the lowest level of income, education, and occupational status (Reitzel et al 2010). In Pakistan, it is estimated that the prevalence of tobacco smoking is 31\% for males and $6 \%$ for females. Among young adults especially the university students in Pakistan, the prevalence of smoking is $23 \%$ (Ahmed et al 2008).

Smoking prevalence among young adults (aged 18-24) in 2005 was $24 \%$ in the United States, $33 \%$ for men and $21 \%$ for women (American J of Public Health 2007). A study carried out in Helsinki, Finland showed that the difference in smoking prevalence between boys and girls 15 to 28 years was not statistically significant. During the same study it was shown that the cessation rate was higher among girls than boys (Paavola et al 2001).

Diverse psychological factors have been implicated in the use of cigarette by adolescents and these include peer pressure, smoking parents or siblings, tobacco adverts, absence of restriction at home, stress and unemployment (Zila et al 2010, El-Mhamdi et al 2011, Fawibe et al 2011, Osungbade et al 2008 ) It was equally found out that low-income earners, people with unstable source of income or unemployed have high tendencies to smoke (Yahaya et al 2010, Ding et al 2009, Jill et al 2008). Parental smoking behaviours have also been found to play a key role not only on youth initiation but also in the escalation of their smoking habits. Some studies indicate that youth having at least one smoking parent are more likely to begin smoking themselves (Ahmed et al 2008).

Numerous authors have observed that a young person's decision to smoke is directly influenced by peers' smoking behaviour. Also exposure to smoking in private and public places may also influence tobacco use initiation, maintenance, and cessation (Ahmed et al 2008). A study showed that approximately $75 \%$ of respondents indicated that at least one of their five closest friends smoked cigarette and more than half mentioned that at least one person in their home smokes cigarette (Ahmed et al 2008).

Six out of ten students reported being taught in school about the harmful effects of smoking (Warren et al 2008, Fawibe et al 2011, Odeyemi et al 2009). It was found out that many students do not associate future respiratory and cardiac disease to smoking (Salawu et al 2010). Moreover larger percentage still smoke despite their level of knowledge of the harmful effects (Fawibe et al 2011, Yahaya et al 2010) for reasons like pleasure, addiction, stress and pressure as impetus (Fawibe et al 2011). In Nigeria, 84\% of current smokers believed that tobacco is not harmful to health (Akindele et al 2010) and a separate study in the same country revealed that the proportion of those that ever smoked who could associate cigarette smoking with known health problems were generally low compared to those that never smoked (Osungbade et al 2008).

Global Youth Tobacco Surveillance reported that 7 out of 10 students are willing to stop smoking (Warren et al 2008), and a similar study done in Kwara State, Nigeria showed that only $39.4 \%$ of current smokers are willing to quit (Fawibe et al 2011). Smokers that expressed a willingness to join a cessation programme were $47 \%$ while $73 \%$ of smokers reported that public places should be smoke-free (Ahmed et al 2008).

Young adults are less likely to succeed at quitting smoking compared to older adults even though they are more likely to attempt to quit (Audrain-Mcgovern et al 2009). The likelihood of quitting among young people is strongly dependent on the extent of smoking among their peers. A study carried out found that young people quit 
less if their parents smoke but in another study, parental smoking was unrelated to both quit attempts and cessation (Paavola et al 2001).

Over the years, there has been a great deal of research on smoking cessation and successful quit attempts. However, given that intention to quit smoking is shown to be one of the key steps in the process towards smoking cessation, it is important to study all quit attempts even those that are not successful. In order to adequately address all barriers to smoking cessation among these smokers and increase the proportion of successful quit attempts, it is important to understand the characteristics of smokers who have unsuccessfully tried to quit smoking (Davilla et al 2009).

Smoking cessation among young adults is a challenge to both public health practice and cancer control that will need to be addressed to prevent another generation of smoking attributable morbidity and mortality (Audrain-Mcgovern et al 2009). The most important stated reasons for young people to quit are health and financial reasons. On the other hand, smokers who tried to quit because of social pressure from others were less likely to succeed (Paavola et al 2001). This study seeks to find out smoking prevalence, willingness to quit and factors influencing smoking cessation among university students in a western Nigerian state.

\section{Methodology}

This study was a descriptive cross-sectional study of young adults in tertiary institutions. The sample size was determined using the Fisher's formula; $\mathrm{Z}^{2} \mathrm{PQ} / \mathrm{d}^{2}$ and a sample size of 250 was arrived at while 300 was sampled. Multi-stage sampling technique was adopted to select the students that were interviewed. There are two universities in Ekiti State: Afe Babalola University, Ado- Ekiti and University of Ado-Ekiti. The study involved students in the two institutions. In the first stage of sampling, five departments were selected in each of the universities using simple random sampling technique by balloting.

In the second stage, systematic sampling was used to select the respondents. The total list of the students in the selected departments served as the sampling frame and the sampling interval was determined by dividing the sampling frame by the sample size. The respondents were identified by matriculation numbers, departments, levels of education and the number on the sampling frame for easy tracing. Students that are not around during the time of the study or those that are not willing to participate were excluded from the study. Such students were replaced by the next person in the sampling frame.

The questionnaire was semi-structured and it was self-administered. It was designed to elicit information on socio-demographic characteristics, cigarette smoking pattern, willingness to quit and smoking cessation pattern. The questionnaire was pre-tested on 30 students of College of Education, Ikere Ekiti and necessary corrections were made thereafter. The questionnaires were edited manually for errors and entered into the computer for analysis using Epi-Info version 3.4.1. Ethical clearance for the study was sought from the Ethical Committee of the Federal Medical Centre, Ido-Ekiti.

\section{Result}

Sixty six students had a history of smoking (22\%) of the total population interviewed.

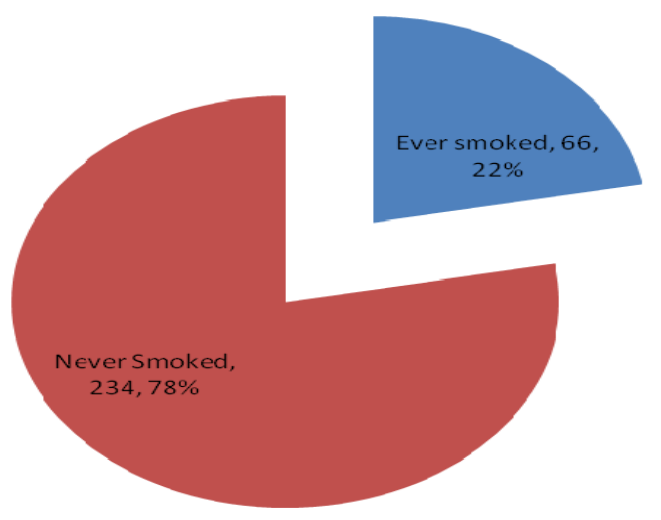

Figure 1. Prevalence of ever smoked 
Ever smoked: Those who have taken up to 100 sticks ofcigarette in their lifetime, irrespective of whether he/she still smokes (Husten 2007)

Never smoked: Those who have not taken up to 100 sticks of cigarette in his/her lifetime (Husten 2007).



Figure 2. Proportion of ever smoked that have ceased smoking

Currently smokes: Those who have taken up to 100 sticks of cigarette in their lifetime and has smoked in the last one year (Husten 2007).

Ceased smoking: Those who have taken up to 100 sticks of cigarette in their lifetime, but has stopped smoking for up to one year before this study (Husten 2007).

The age distribution of these respondents ranged from 18 to 30 years while the mean age of students interviewed was $21.73 \pm 2.52$. A larger proportion of the students were males, accounting for $62(93.9 \%)$ out of the 66 respondents while $56(84.4 \%)$ were Christians. Respondents with a monthly expenditure of less than 5000 naira (less than 31.42 dollars) were 23 (34.8\%), 28 (48.7\%) spent between 5000 and 10000 naira (31.43-62.83 dollars). It was however noted that $15(22.7 \%)$ respondents had a monthly expenditure of more than 10000 naira (greater than 62.83 dollars). The mean monthly expenditure was 8,820 naira (55.42 US dollars).

Table 1. Socio-demographic characteristics of respondents that ever smoked

\begin{tabular}{|c|c|}
\hline Variable & Frequency (Percentage) $\mathrm{N}=66$ \\
\hline \multicolumn{2}{|l|}{ Age Group (Years) } \\
\hline $18-20$ & $22(33.3)$ \\
\hline $21-25$ & $42(63.6)$ \\
\hline $26-30$ & $2(3.0)$ \\
\hline \multicolumn{2}{|l|}{ Mean Age: $21.73+2.52$ (Range: $18-30$ ) } \\
\hline \multicolumn{2}{|l|}{ Sex } \\
\hline Male & $62(93.9)$ \\
\hline Female & $4(6.1)$ \\
\hline \multicolumn{2}{|l|}{ Religion } \\
\hline Christianity & $56(84.4)$ \\
\hline Islam & $10(15.2)$ \\
\hline \multicolumn{2}{|l|}{ Monthly Expenditure (Naira/Dollars) } \\
\hline$\leq 5000(\leq 31.42$ US Dollars $)$ & $23(34.8)$ \\
\hline 5000-10000 (31.43-62.83 US Dollars) & $28(48.7)$ \\
\hline$>10000$ (>62.83 US Dollars) & $15(22.7)$ \\
\hline Mean Monthly Expenditure: 8,820 (55.42 US D & (41.51 US Dollars) \\
\hline
\end{tabular}

Half of the respondents $33(50 \%)$ smoked mainly in parties/clubs, with $16(24.2 \%)$ found to smoke more in friend's houses, $10(15.2 \%)$ smoked in schools, while $7(10.6 \%)$ said they smoked mainly in the hostel. Mentholated cigarettes were found to be smoked by $59(89.4 \%)$ respondents while $7(10.6 \%)$ smoked non-mentholated cigarettes. At one point in time 47 (71.2\%) had been asked to stop smoking, while 19 (28.8\%) of the respondents had never been asked to quit smoking. Out of the 47 that had been asked to quit, $32(68.1 \%)$ were asked by friends, $8(17 \%)$ by parents, and $7(14.9 \%)$ by a health worker. 
Table 2. Cigarette smoking pattern and factors that influence smoking cessation

\begin{tabular}{|c|c|}
\hline Characteristic & Frequency (Percent) \\
\hline Main location of smoking & $\mathbf{N}=66$ \\
\hline Parties/Clubs & $33(50.0)$ \\
\hline Friend's house & $16(24.2)$ \\
\hline In school & $10(15.2)$ \\
\hline Hostel & $7(10.6)$ \\
\hline Type of cigarette & $\mathrm{N}=66$ \\
\hline Mentholated & $59(89.4)$ \\
\hline Non Mentholated & $7(10.6)$ \\
\hline Ever asked to quit & $\mathrm{N}=66$ \\
\hline Yes & $47(71.2)$ \\
\hline No & $19(28.8)$ \\
\hline Asked to quit by who & $\mathrm{N}=47$ \\
\hline Friends & $32(68.1)$ \\
\hline Parents & $8(17.0)$ \\
\hline Health worker & $7(14.9)$ \\
\hline Ever asked proof of age when buying cigarette & $\mathrm{N}=66$ \\
\hline Yes & $17(25.8)$ \\
\hline No & $49(74.2)$ \\
\hline Smoking restrictions at home & $\mathrm{N}=66$ \\
\hline Yes & $46(66.9)$ \\
\hline No & $20(30.3)$ \\
\hline Influence to smoke & $\mathrm{N}=66$ \\
\hline Friends & $35(53.0)$ \\
\hline Adverts & $25(37.9)$ \\
\hline Siblings & $6(9.1)$ \\
\hline \multicolumn{2}{|c|}{$\begin{array}{l}\text { Respondents who were asked for proof of age when buying cigarette were found to be } 17(25.8 \%) \text {, while } 49 \\
(74.2 \%) \text { had never been asked for proof of age. Smoking restrictions at home were experienced by } 46(66.9 \%) \text {, } \\
\text { while } 20(30.3 \%) \text { do not have restrictions at home. A little more than half of the respondents } 35(53 \%) \text { were } \\
\text { influenced by friends to smoke, } 25(37.9 \%) \text { were influenced by adverts, while } 6(9.1 \%) \text { were influenced by } \\
\text { siblings. Out of the } 41 \text { respondents who were current smokers, } 16(39 \%) \text { were willing to quit, while } 25(61 \%) \\
\text { were not willing. At one point in time, } 55(83.3 \%) \text { of all respondents had attempted to quit, while } 11(16.7 \%) \text { had } \\
\text { however made no such attempt. }\end{array}$} \\
\hline \multirow{2}{*}{\multicolumn{2}{|c|}{$\begin{array}{l}\text { Of those who had attempted quitting, } 41(74.5 \%) \text { did so because of health problems, } 8(14.5 \%) \text { did so due to } \\
\text { pressure from friends and family, while } 6(10.9 \%) \text { did because of fear of disease. Currently, } 25(37.9 \%) \text { have } \\
\text { currently ceased smoking, while } 41(62.1 \%) \text { do currently smoke. Out of those who have ceased smoking, } 17 \\
(68 \%) \text { did so because it was hazardous to health and } 8(32 \%) \text { because they lost interest. Knowledge of premature } \\
\text { death as a result of smoking was expressed by } 51(77.3 \%) \text { respondents, while } 15(22.7 \%) \text { did not know. Smoking } \\
\text { control was advocated for by } 55(83.3 \%) \text { respondents, while } 11(16.7 \%) \text { however disagreed. } \\
\text { Table 3. Willingness to quit smoking and factors that affect smoking cessation }\end{array}$}} \\
\hline & \\
\hline Characteristic & Frequency (Percent) \\
\hline Willingness to quit smoking by Current smokers & $\mathbf{N}=41$ \\
\hline Willing & $16(39.0)$ \\
\hline Not willing & $25(61.0)$ \\
\hline Attempt to quit & $N=66$ \\
\hline Yes & $55(83.3)$ \\
\hline M & $11(16.7)$ \\
\hline Why attempt to quit & $\mathbf{N}=\mathbf{5 5}$ \\
\hline Health problems & $41(74.5)$ \\
\hline Pressure from family and friends & $8(14.5)$ \\
\hline Fear of disease & $6(10.9)$ \\
\hline Smoking Cessation & $\mathrm{N}=66$ \\
\hline Ceased smoking & $25(37.9)$ \\
\hline Currently smokes & $41(62.1)$ \\
\hline Reasons for smoking cessation & $\mathrm{N}=\mathbf{2 5}$ \\
\hline Hazardous to health & $17(68.0)$ \\
\hline Lost interest & $8(32.0)$ \\
\hline Smoking can lead to premature death & $N=66$ \\
\hline Yes & $51(77.3)$ \\
\hline No & $15(22.7)$ \\
\hline Smoking should be controlled & $\mathrm{N}=66$ \\
\hline Yes & $55(83.3)$ \\
\hline No & $11(16.7)$ \\
\hline
\end{tabular}


In factors affecting smoking cessation, $47.1 \%$ of those that believed smoking can lead to premature death successfully stopped smoking, while $93.3 \%$ of those who do not believe that smoking can lead to premature death currently smoke with a p-value of 0.01 .

Table 4. Factors affecting smoking cessation

\begin{tabular}{|c|c|c|c|c|}
\hline \multicolumn{5}{|c|}{ Smoking cessation status } \\
\hline & Currently smokes & Ceased smoking & $\mathbf{X}^{2}$ & p-value \\
\hline \multicolumn{5}{|c|}{ Smoking can lead to premature death } \\
\hline Yes & $27(52.9)$ & $24(47.1)$ & 6.4 & 0.0113 \\
\hline No & $14(93.3)$ & $1(6.7)$ & & \\
\hline \multicolumn{5}{|l|}{ Ever asked to quit } \\
\hline Yes & $35(74.5)$ & $12(25.5)$ & 10.6 & 0.0011 \\
\hline No & $6(31.6)$ & $13(68.4)$ & & \\
\hline \multicolumn{5}{|l|}{ Age Group } \\
\hline $18-20$ & $11(50.0)$ & $11(50.0)$ & 6.2 & 0.0451 \\
\hline $21-25$ & $30(71.4)$ & $12(28.6)$ & & \\
\hline $26-30$ & $0(0.0)$ & $2(100.0)$ & & \\
\hline \multicolumn{5}{|c|}{ Monthly Expenditure (Naira/US Dollars) } \\
\hline$\leq 5000(\leq 31.42$ USD $)$ & $14(60.9)$ & $9(39.1)$ & 0.1 & 0.9500 \\
\hline $5000-10000(31.43-62.83$ & $18(64.3)$ & $10(35.7)$ & & \\
\hline USD) & & & & \\
\hline$>10000(>62.83$ USD $)$ & $9(60.0)$ & $6(40.0)$ & & \\
\hline \multicolumn{5}{|l|}{ Smoking Restriction } \\
\hline Yes & $28(60.9)$ & $18(39.1)$ & 0.1 & 0.7500 \\
\hline No & $13(65.0)$ & $7(35.0)$ & & \\
\hline \multicolumn{5}{|l|}{ Main location of smoking } \\
\hline Parties/Clubs & $19(57.6)$ & $14(42.4)$ & 0.86 & 0.8300 \\
\hline Friend's house & $11(68.8)$ & $5(31.3)$ & & \\
\hline School & $6(60.0)$ & $4(40.0)$ & & \\
\hline Hostel & $5(71.4)$ & $2(28.6)$ & & \\
\hline
\end{tabular}

Never being asked to quit smoking was positively associated with smoking cessation as $68.4 \%$ of those who were never asked to quit actually ceased smoking while only $25.5 \%$ of those that were asked to quit successfully ceased smoking. Smoking cessation was also influenced by the increasing age of the respondents, this was also statistically significant with a p-value of 0.05 as shown by those within the age bracket of 26-30 yrs that had 2 respondents who had a history of smoking but now had ceased smoking.

\section{Discussion}

The study investigated the prevalence, willingness to quit and factors influencing smoking cessation among university students in a western Nigerian state. The prevalence of smoking among the respondents was found to be $22 \%$ out of which $62 \%$ currently smoke while $38 \%$ had quit smoking. The prevalence of smoking which was found to be $22 \%$ is similar to a prevalence of $26 \%$ found in a study carried out among university students in Pakistan (Ahmed et al 2008).

This is also consistent with the findings in other studies in Nigeria in which prevalence of cigarette smoking was found to be $20.5 \%$, of which $56.5 \%$ are current smokers while $43.9 \%$ were ex-smokers (Evelyn et al 2007). However, in China those that ever smoked were $61.0 \%, 78.7 \%$ of which are current smokers while $21.3 \%$ were ex-smokers (Adekunle et al 2011). Several reasons were given for quitting tobacco use by ex-smokers, in other studies done in Nigeria, $50 \%$ gave health reasons, $22.2 \%$ because they wanted to, $11.1 \%$ as a result of social pressure from parents or religious authorities, while only 3\% stopped for financial reasons (Akindele et al 2010, Muula et al 2007). Similarly this study showed that health problems $(74.5 \%)$, pressure from family and friends $(14.5 \%)$, fear of disease $(10.9 \%)$ and loss of interest are reasons for quitting.

Current smokers' willingness to quit as found in this study was $39.0 \%$. Another study carried out in North central Nigeria revealed a similar willingness to quit of $39.4 \%$ by current smokers (Fawibe et al 2011). This study also found that most smokers quit for health reasons $(74.5 \%)$ therefore anti-tobacco education with emphasis on the health complications should continue and be made part of the curriculum in schools and colleges (Akindele et al 2010). Pressure from family and friends, religious authorities against smoking tend to increase the number of ex-smokers, so a healthy familial relationship and religious involvement by adolescence is advocated (American Cancer Society 2009).

The influence of friends in smoking practices was clearly higher than other influences as $53.0 \%$ were influenced by friends. This shows that a young person's decision to smoke is directly influenced by peers' smoking behaviour. However, the influence of family members was much lower as $9.1 \%$ were influenced by siblings. The 
explanation for this might be the most frequent location of smoking practices which was in parties $(50 \%)$ and high levels of smoking restrictions in the home among our respondents (66.9\%).

Smoking cessation was high in those who believed that smoking can lead to premature death (47.1\%) compared with those who did not believe that smoking could lead to premature death $(6.7 \%)$. Therefore, the importance of health education on the consequences of cigarette smoking and the need to quit will be appropriate in this age group because the age group experiment with many things including smoking.

Most respondents (83.3\%) have attempted to quit smoking. This is relatively high when compared with another study in China where 53.1\% have attempted to quit smoking (Ding et al 2009). The higher level of attempt to quit in this study may be because of health problems associated with smoking as $74.5 \%$ of those that attempted smoking cessation did so because of health problems. However in another Chinese study (Ceraso et al 2009) $4.6 \%$ of former smokers quit because of illness. Health care providers should therefore continue to advise their patients concerning the health problems associated with smoking.

A recently published study which used data from China National Health Services survey conducted in 2003 found that quitting increased with age among Chinese smokers (Ding et al 2009). This is consistent with the findings in this study where $100 \%$ of respondents in the older age group (26-30 years) have successfully quit smoking compared with the younger age groups $(\mathrm{p}=0.011)$. The implication of this finding is that health education should focus more on the younger age group. However, the fact that only $37.9 \%$ of our respondents that ever smoked succeeded at smoking cessation highlights the difficulty most smokers have with achieving successful cessation.

Knowledge of the health implications from smoking was shown to be a major factor for smoking cessation in our respondents. Peer pressure was a major influence on respondents' smoking habit while the main location of smoking cigarettes being parties/clubs contributed to their smoking habit. Diagnosis of health problems play a major role in smoke quitting attempts while belief that it can lead to premature death influence smoking cessation. However, being asked to quit smoking without a good understanding does not contribute positively to successful smoking cessation.

\section{Conclusion}

Promotion of health education on the consequences of smoking cigarettes targeted at the vulnerable age group especially in parties where they are frequently influenced to smoke will be a major factor in influencing smoking cessation. Peer education in schools emphasizing knowledge of the health implications from smoking as well as early diagnosis of smoking related health problems will go a long way in encouraging smoking cessation.

\section{References}

Adekunle S, Omotosho M, Tanimola A., \& Oladimeji B. (2011). Effects of health education on cigarette smoking habits of young adults in tertiary institutions in a northern Nigerian state. Health Science Journal, $5(3), 12-20$.

Ahmed R, Rizwan-ur-Rashid, McDonald PW., \& Ahmed SW. (2008). Prevalence of cigarette smoking among young adults in Pakistan. JPMA, 58(11), 597-601

Akindele OA, Babalola F, Adesola OS., \& Eme TO. (2010). Tobacco use amongst out of school adolescents in a Local Government Area in Nigeria. Substance Abuse Treatment, Prevention, and Policy, 5, 24. http://dx.doi.org/10.1186/1747-597X-5-24

Al-Mohamed HI., \& Amin TT. (2010). Pattern and prevalence of smoking among students at King Faisal University, Al Hassa, Saudi Arabia. Eastern Mediterranean Health Journal, 16(1), 56-64.

American Cancer Society Atlanta, Georgia. (2009). The Global Tobacco Epidermic, 6-8.

Audrain-Mcgovern J, Rodriguez D, Epstein LH, Rodgers K, Cuevas J., \& Wileyeto EP. (2009). Young Adult Smoking: What factors differentiate ex-smokers, smoking cessation treatment seekers and non-treatment seekers? Addicts behaviour, 34(12), 1036-1041.

Breitling LP, Rothenbacher D, Stegmaier C, Raum E., \& Brenner H. (2009). Older Smoker's Motivation and Attempts to Quit Smoking. Deutsches Arzteblatt International, 106(27), 451-455.

Ceraso M, McElroy J.A, Kuang X, Vila P.M, Du X, Lu L. et al. (2009). Smoking, Barriers to Quitting, and Smoking-Related Knowledge, Attitudes, and Patient Practices Among Male Physicians in China. Public Health Research, Practice and Policy, 6(1), 1-6.

Davilla E.P, Zhao W, Lee D.J. et al. (2009). Correlates of smoking quit attempts: Florida Tobacco Callback Survey, 2007. Tobacco Induced Diseases, 5, 10. http://dx.doi.org/10.1186/1617-9625-5-10 
Ding D, Melbourne FH, Ming JC. Richard H, Pinpin Z, Hua F., \& Suzanne CH. (2009). Employment and social determinants of smoking in urbanizing China: A representative survey. Nicotine Tobacco Research, 11(7), 779-784. http://dx.doi.org/10.1093/ntr/ntp060

Edwards VJ, Anda RF, Gu D, Dube SR., \& Felliti VJ. (2007). Adverse Childhood Experiences and Smoking Persistence in Adults with Smoking-Related Symptoms and Illness. The Permanente Journal, 11(2), 5-13.

El-Mhamdi S, Wolfcarius-Khiari G, Mhalla S, Ben Salem K., \& Soltani SM. (2011). Prevalence and predictors of smoking among adolescent schoolchildren in Monastir, Tunisia. Eastern Mediterranean Health Journal, 17(6), 523-8.

Etter JF, Prokhorov AV., \& Perneger TV. (2002). Gender differences in the psychological determinants of cigarette smoking. Addiction, 97(6), 733-43. http://dx.doi.org/10.1046/j.1360-0443.2002.00135.x

Evelyn P, Wei Z, Margaret B, Monica W., \& Youngie H. (2007). Willingness to quit smoking. Florida Tobacco Callback Survey.

Fawibe AE., \& Shittu AO. (2011). Prevalence and characteristics of cigarette smokers among undergraduates of the University of Ilorin, Nigeria. Niger J Clin Pract, 14, 201-5. http://dx.doi.org/10.4103/1119-3077.84016

Feryal CC, Serhat C., \& Unal E. (2009). Smoking Determinants in Turkish University Students. International Journal of Environmental Research and Public Health, 6(8), 2248-2257. http://dx.doi.org/10.3390/ijerph6082248

Guoze F, Yuan J, Qiang, Hua-Hie Y, Tara Elton-M, Jilan Y, Lin Li, Natalie S., \& Geoffrey T Fong. (2010). Individual level factors associated with intentions to quit smoking among adult smokers in six cities of China. Tobacco control, 2, i6- i11.

Husten, C. G. (2007). Smoking Cessation in Young Adults. American Journal of Public Health, 97(8), 1354-1356. http://dx.doi.org/10.2105/AJPH.2007.117358

Jill CM, Edward MS., \& Rachel FT. (2008). Socioeconomic and drug use determinants of smoking status in a Canadian urban adult population of black African descent. Nicotine Tobacco Research, 10(8), 1319-1325. http://dx.doi.org/10.1080/14622200802238894

Muula AS., \& Mpabulungi L. (2007). Cigarette smoking prevalence among school-going adolescents in two African capital cities: Kampala Uganda and Lilongwe Malawi. African Health Science, 7(1), 45-9.

Odeyemi KA, Osibogun A, Akinsete AO., \& Sadiq L. (2009). The Prevalence and Predictors of Cigarette Smoking among Secondary School Students in Nigeria. The Nigerian Postgraduate Medical Journal, 16(1), 40-45.

Osungbade KO., \& Oshiname FO. (2008). Determinants of cigarette smoking among senior secondary school students in a rural community of southwest Nigeria. Nigerian Jounal of Medicine, 17(1), 40-4. http://dx.doi.org/10.4314/njm.v17i1.37353

Paavola M., Vartiainen E., \& Puska P. (2001). Smoking Sessation between teenage years and adulthood. Health Education Research, 16(1), 49-57. http://dx.doi.org/10.1093/her/16.1.49

Reid JL, Hammond, Boudreau C, Fong GT., \& Saipush M. (2010). Socioecononmic disparities in quit intentions, quit attempts and smoking abstinence among smokers in four western countries: Findings from the International Tobacco Control Four Country Survey. Nicotine \& Tobacco Research, 12(1), S20-S33. http://dx.doi.org/10.1093/ntr/ntq051

Reitzel LR, Mazas CA, Cofta-Woerpel L, Li Y, Cao Y, Businelle MS, Cinciripini PM., \& Wetter DW. (2010). Subjective Social Status Affects Smoking Abstinence During Acute Withdrawal Through affective Mediators. Addiction, 105(5), 928-936. http://dx.doi.org/10.1111/j.1360-0443.2009.02875.x

Salawu F, Danburam A, Isa B., \& Agbo J. (2010). Cigarette smoking habits among adolescents in northeast Nigeria. The Internet Journal of Epidemiology, 8(1).

Warren CW, Jones NR, Peruga A, Chauvin J, Baptiste JP, Costa de Silva V, el Awa F,Tsouros A, Rahman K, Fishburn B, Bettcher DW., \& Asma. (2008). Centre for Disease and Prevention (CDC): Global Youth Tobacco Surveillance, 2000-2007. MMWR Surveill, 57(1), 1-28.

Yahya SJ, Hammangabdo A., \& Omotara BA. (2010). Factors influencing the onset of cigarette smoking among adolescents in Konduga local government area. Nigerian Journal of Medicine, 19(3), 275-8. http://dx.doi.org/10.4314/njm.v19i3.60184

Zila MS, Emerita SO, Silvia SM, Jasjit SA., \& Ana RN. (2010). Adolescent gender differences in the determinants of tobacco smoking: a cross sectional survey among high school students in São Paulo. BioMed Central D Public Health, 10, 748. 